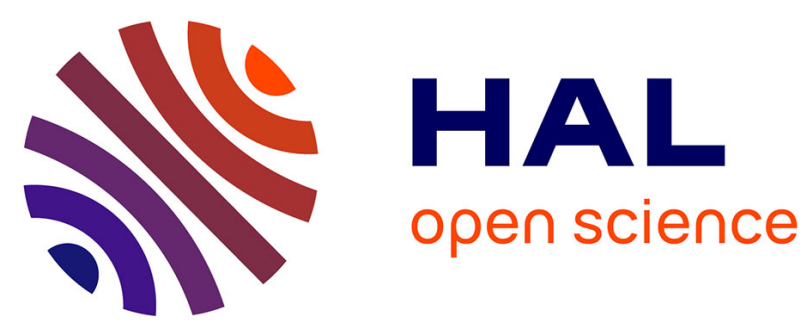

\title{
Enhancement of mechanical properties and chemical durability of Soda-lime silicate glasses treated by DC gas discharges
}

Matthieu Chazot, Maxime Paraillous, Stéphane Jouannigot, Lionel Teulé-Gay, Jean-Paul Salvetat, Frederic Adamietz, Ricardo Alvarado Meza, Lara Karam, Angeline Poulon-Quintin, Thierry Cardinal, et al.

\section{To cite this version:}

Matthieu Chazot, Maxime Paraillous, Stéphane Jouannigot, Lionel Teulé-Gay, Jean-Paul Salvetat, et al.. Enhancement of mechanical properties and chemical durability of Soda-lime silicate glasses treated by DC gas discharges. Journal of the American Ceramic Society, 2021, 104 (1), pp.157-166. 10.1111/jace.17438 . hal-02955390

\section{HAL Id: hal-02955390 https://hal.science/hal-02955390}

Submitted on 9 Oct 2020

HAL is a multi-disciplinary open access archive for the deposit and dissemination of scientific research documents, whether they are published or not. The documents may come from teaching and research institutions in France or abroad, or from public or private research centers.
L'archive ouverte pluridisciplinaire HAL, est destinée au dépôt et à la diffusion de documents scientifiques de niveau recherche, publiés ou non, émanant des établissements d'enseignement et de recherche français ou étrangers, des laboratoires publics ou privés. 


\title{
Enhancement of mechanical properties and chemical durability of Soda-lime silicate glasses treated by DC gas discharges
}

\author{
Matthieu Chazot ${ }^{1,2}$ \\ Jean-Paul Salvetat ${ }^{4}$ \\ $\left.\right|_{\text {Maxime Paraillous }}{ }^{2} \quad$ Stephane Jouannigot $^{3}$ \\ Frederic Adamietz ${ }^{1}$ \\ Angeline Poulon ${ }^{2}$ \\ Thierry Cardinal ${ }^{2}$ \\ Ricardo Alvarado-Meza ${ }^{1}$ \\ Lionel Teulé-Gay ${ }^{2}$ \\ Lara Karam $^{1}$ \\ Evelyne Fargin ${ }^{2}$ \\ Marc Dussauze ${ }^{1}$
}

\author{
${ }^{1}$ Univ. Bordeaux, ISM, CNRS UMR 5255, \\ Talence, France \\ ${ }^{2}$ Univ. Bordeaux, ICMCB, CNRS UMR \\ 5026, Pessac, France \\ ${ }^{3}$ Univ. Bordeaux, LCTS, CNRS UMR 5801, \\ Pessac, France \\ ${ }^{4}$ Univ. Bordeaux, PLACAMAT, CNRS \\ UMS 3626, Pessac, France \\ Correspondence \\ Matthieu Chazot, Univ. Bordeaux, ISM, \\ CNRS UMR 5255, F-33400 Talence, \\ France. \\ Email: matthieuanthonyalexandre.chazot@ \\ ucf.edu \\ Funding information \\ IdEx Bordeaux, Grant/Award Number: \\ ANR-10-IDEX-03-03; H2020 Marie \\ Skłodowska-Curie Actions, Grant/Award \\ Number: 823941; Centre National de la \\ Recherche Scientifique, Grant/Award \\ Number: EMERGENCE @ INC2019; \\ SATT Aquitaine; Nouvelle Aquitaine, \\ Grant/Award Number: SOLR2; French \\ RENATECH; FEDER; Region Aquitaine
}

\begin{abstract}
We report for the first time a study on non-contact thermal poling of soda lime silicate glasses using DC gas discharge. In this work, the formation of a glow discharge is evidenced during the thermal poling treatment (longer than 30 minutes). The hardness and the chemical durability of glasses poled under different conditions (contact or non-contact) and atmospheres (nitrogen or air) are measured and compared to that of un-poled reference glass. The results reveal enhanced mechanical and chemical properties for samples poled under nitrogen as compare to air poled or soda lime silicate glass samples. A structural and chemical analysis of surface of the glass using IR-reflectance measurement and ToF-SIMS is also presented. The formation of a "silica-like" layer on the surface of nitrogen poled glasses is observed, which is likely associated with the enhancement of surface properties. On the other hand, the introduction of protons beneath the surface of glasses poled under air leads to the formation of a hydrated alkaline earth silica layer. Based on the observations a mechanism behind the sustainability of the plasma under DC conditions is proposed.
\end{abstract}

\section{\begin{tabular}{l|l}
1 & INTRODUCTION
\end{tabular}}

Mechanical and chemical durability enhancement of glass surfaces are major issues for glass manufacturers. For example, the development of compact mobile devices require glass-based components with a better mechanical resistance. Also many outdoor systems like solar panels or mirrors in solar harvesting system requires high optical transparency, chemical and mechanical stability, and cost-effective production scalability. ${ }^{1}$ Currently, one of the most commercialized and used glasses are soda-lime silicate glasses for their high transparency and low fabrication cost. In order to enhance their mechanical properties, different techniques such as ion exchange, de-alkalization or tempering can be employed..$^{2-5}$ In addition, thermo-electrical polarization treatment has been reported to modify/functionalize the surface chemical and mechanical properties of various glasses, including soda-lime silicate glasses. ${ }^{6-9}$ This process begins with the application of a high DC voltage on a heated glass sample to induce charge dissociations within the glass matrix for a controlled duration, followed by a decrease in temperature while maintaining the DC field. The process induces cations to migrate, leaving a depletion layer beneath the anode surface associated with a reorganization of the glass network. ${ }^{8,10}$ Such approach allows the development of innovative multilayer glass structures with new compositions previously not 
realized using classical techniques. ${ }^{11}$ In the recent years thermal poling has also shown great potential for glass surface structuring, ${ }^{7,12,13}$ paving the way to the fabrication of innovative architectures on glass surfaces.

Thermal poling presents a great potential as a route to the enhancement of glass surfaces mechanical and chemical durability, since the process leads to the formation of a "silica-like layer" on the surface. ${ }^{14}$ Luo et a ${ }^{15}$ reports the utilization of poling to enhance the hardness of soda lime silicate glasses. Meanwhile, they addressed, like He et al, ${ }^{16}$ the importance of atmospheric control in the poling chamber to avoid the presence of water that leads to proton injection and limits the condensation of the silica glass network. Thermal poling is expected to affect, not only the mechanical properties of soda lime silicate glasses, but also its chemical durability. Early in 1974, Carlson et $\mathrm{al}^{17}$ presented for the first time a study of the difference in etching rate of poled and unpoled silicate glasses exposed to HF, where they reported an enhancement of the chemical durability of poled glasses. Poled glasses have been also reported to exhibit a lower chemical resistance when exposed to KOH solutions. ${ }^{18}$ Recently, AN Kamenskii et $\mathrm{al}^{19}$ combined the use of structured electrodes for poling and preferential chemical etching to create diffraction gratings, demonstrating the potential of thermal poling for glass surface structuring.

Thermal poling is usually performed with electrodes in contact with samples. However, such a contact thermal poling requiring high quality surface planar electrodes is hardly compatible with process protocols currently employed in the industry. Moreover, many applications require the use of non-planar glasses. In order to manage thermal poling on complex 2D geometry, one option would be to perform the poling treatment without contact between glass surfaces and electrodes.

In this study, we present the utilization of a Dielectric Barrier Discharge (DBD) as an alternative non-contact electrical polarization method to improve mechanical properties and chemical durability of soda lime silicate glasses. The impact of the gas used on polarized glass' compositions and surface structure has been characterized by infrared spectroscopy and SIMS. We also focus on the particularities of the discharge during this non-contact poling treatment of an ionic glass as compared to classical dielectric barrier discharge.

\section{EXPERIMENTAL DETAILS}

The soda-lime glass used for this study is a commercial Menzel-Gläser glass of composition $72.20 \% \mathrm{SiO}_{2}-14.30 \%$ $\mathrm{Na}_{2} \mathrm{O}-1.20 \% \mathrm{~K}_{2} \mathrm{O}-6.40 \% \mathrm{CaO}-4.30 \% \mathrm{MgO}-1.20 \%$ $\mathrm{Al}_{2} \mathrm{O}_{3}-0.03 \% \mathrm{Fe}_{2} \mathrm{O}_{3}-0.30 \% \mathrm{SO}_{3}$ (weight \%) as reported by Gerhard Menzel GmbH. Glasses were poled at $260^{\circ} \mathrm{C}$ and $1.5 \mathrm{kV}$ for 30 minutes in a controlled atmosphere chamber

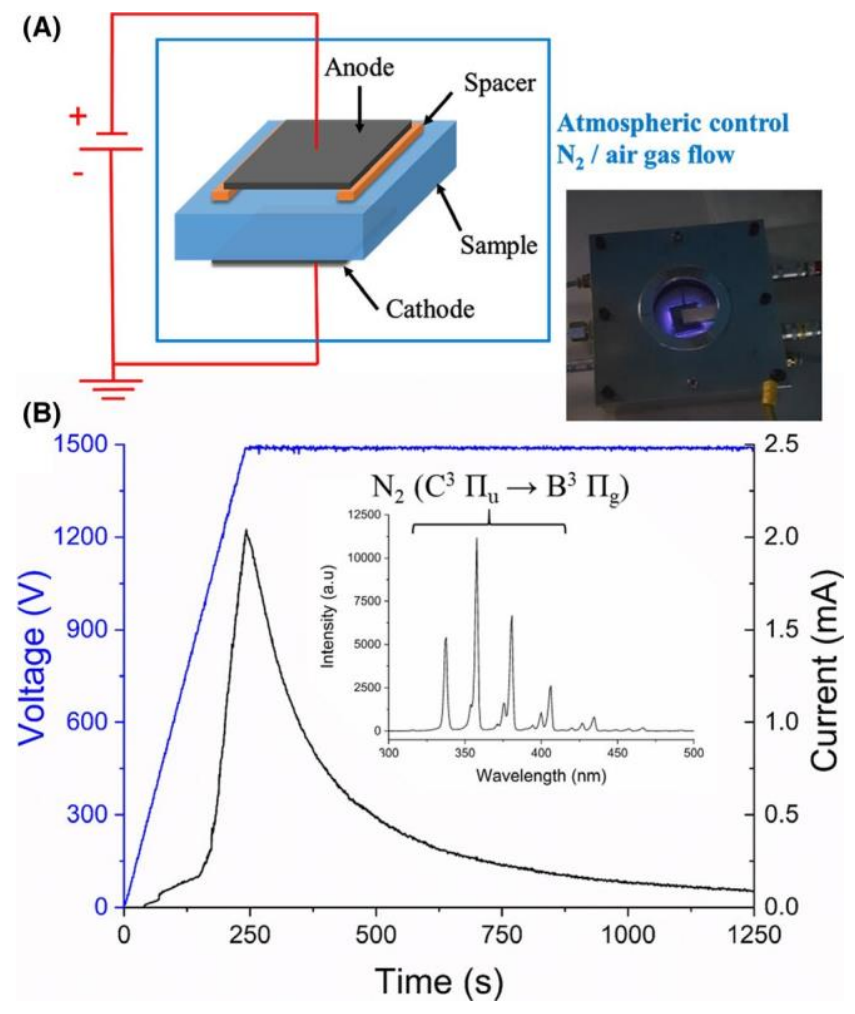

F I G URE 1 A, Scheme of the poling set-up used for non-contact poling with photography of the poling cell during poling treatment; B, Graphic presenting the curves of the applied voltage and the measured current. On the inset is reported the emission spectrum measured during non-contact poling treatment within $300-500 \mathrm{~nm}$ spectral range

under air or $\mathrm{N}_{2}$ gas flow. The voltage was increased at a rate of $375 \mathrm{~V} / \mathrm{min}$ until it reaches a target value of $1.5 \mathrm{kV}$. In order to freeze the poling process, the high voltage applied on the sample was maintained constant while the sample was cooled down to room temperature. Figure 1A presents the schematic of the poling sandwich where borosilicate glasses of $150 \mu \mathrm{m}$ thickness were used as spacers. $\mathrm{N}$-doped silicon electrodes were used at the cathode and anode for poling without contact, while an ITO thin film with resistivity of 8-12 $\Omega$.sq was used at the anode for poling with contact to avoid anodic bonding during the poling treatment. A borosilicate thin glass slide with dimensions of $25 \times 25 \mathrm{~mm}(\mathrm{~L} \times \mathrm{W})$ and $150 \mu \mathrm{m}$ thickness was placed between the soda-lime glass sample and the cathode in order to avoid an accumulation of cations at the surface of the sample that could leads to a deterioration of the optical properties. The dimension of the soda-lime glass sample was $25 \times 25 \times 1 \mathrm{~mm}$, while the electrodes had dimensions of $20 \times 20 \times 1 \mathrm{~mm}(\mathrm{~L} \times \mathrm{W} \times \mathrm{H})$. The size of the borosilicate spacers was $10 \times 3 \times 0.15 \mathrm{~mm}(\mathrm{~L} \times \mathrm{W} \times \mathrm{H})$.

IR-reflectance spectra were obtained using a Bruker VERTEX70v spectrophotometer equipped with a DTGS detector. Two hundred scans were made on each sample with a spectral resolution of $4 \mathrm{~cm}^{-1}$. In order to avoid atmospheric water vapor and $\mathrm{CO}_{2}$ absorptions, the spectrometer 
F I G U R E 2 GD-OES (left) and ToF-SIMS (right) composition profile in logarithmic scale of the non-contact poled glasses under nitrogen atmosphere

\section{GD-OES measurement}

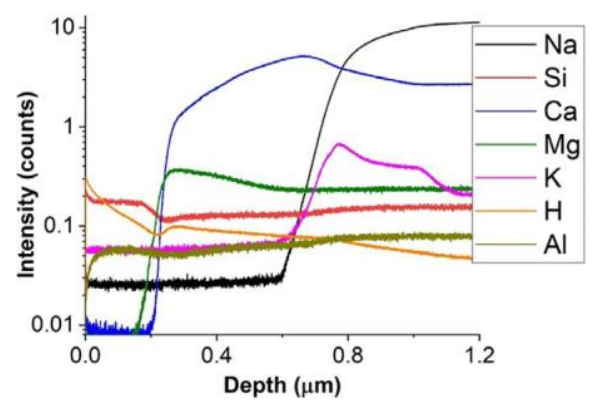

ToF-SIMS measurement

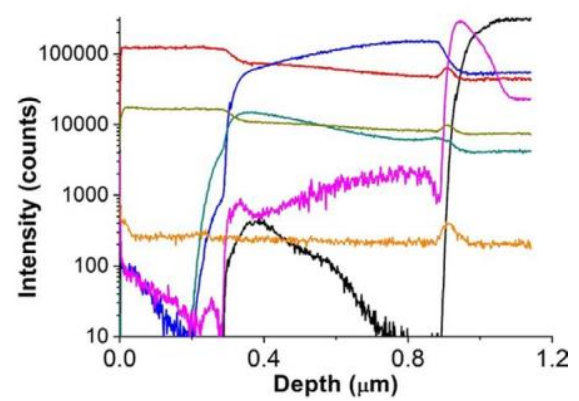

was put under vacuum. Reflectance experiments were carried out by the use of an external reflection set-up with an incidence angle of $12^{\circ}$. The complex refractive indices were retrieved by Kramers-Krönig analysis of specular reflectance spectra. In this work, the infrared spectra were expressed in term of normalized imaginary part of the dielectric constant " $\varepsilon "$. Infrared (IR) absorption spectra were collected using a PerkinElmer Frontier FTIR. The spectral resolution used was of $4 \mathrm{~cm}^{-1}$ and 64 accumulations were made for every sample.

Optical Emission Spectrometry (OES) measurements were carried out using an Oceanoptics QE65000, within range of 300-500 nm and an integration time of 5 seconds. The light was collected using a $2 \mathrm{~m}$ Premium fiber with a core diameter of $400 \mu \mathrm{m}$.

ToF-SIMS measurements of glasses were carried out using a TOF.SIMS 5 time-of-flight secondary ion mass spectrometer (IONTOF GmbH), equipped with a dual-source sputter gun and a liquid metal ion gun (LMIG) orientated at $45^{\circ}$ to the sample surface. The LMIG provided a 10 micron-diameter spot $30 \mathrm{keV} \mathrm{Bi}^{+}$ion beam, operating at an ion current of $2 \mathrm{pA}$, raster scanned randomly in the region of interest. Depth profiles were performed in a non-interlaced mode with sputtering cycles using $2 \mathrm{keV} \mathrm{O}_{2^{+}}$ions at a current of $600 \mathrm{nA}$ and cycle time of $50 \mu \mathrm{s}$, over an area of $300 \times 300 \mu \mathrm{m}$, interleaved with secondary ion images generated by the LMIG over an area of $100 \times 100 \mu \mathrm{m}$ in the center of the sputtered region. A $20 \mathrm{eV}$ electron flood gun was used to compensate for charging effects during the measurements. Surface potential was adjusted to optimize the analyzer transmission.

GD-OES analysis was performed with a glow discharge spectrometer HORIBA GD profilometer 2, using a polychromator enabling to follow the evolution profile of 40 elements simultaneously. An Argon pressure of $350 \mathrm{~Pa}$ and a power of $45 \mathrm{~W}$ (Radio-frequency at $13.56 \mathrm{MHz}$ ) were applied for the erosion of the material. The acquisition and the data treatment were carried out using a Quantum (HORIBA JobinYvon) software.

Depth of SIMS and GD-OES craters were measured with an optical profilometer using white light interferometry (WYKO NT1100). Depths rate values are qualitative as the ablation rate highly depends on the chemical nature of the ablated layer.
Chemical durability tests were carried out by immerging glass samples in saline water with a concentration of $35 \mathrm{~g} / \mathrm{L}$ during 72 hours. In order to accelerate the durability test the solution was stirred at a temperature of $65^{\circ} \mathrm{C}$ to ensure the solution homogeneity all along the treatment.

Nanoindentation tests were carried out with an NT600 nanoindenter manufactured by Micro Materials Limited (Wrexham). The indenter tip used during our experiments is a Berkovitch one (triangular pyramid). The Oliver and Pharr analysis method ${ }^{20}$ was used to extract the hardness $\mathrm{H}=\mathrm{P} / \mathrm{A}$ from data measurements, where $\mathrm{P}$ and $\mathrm{A}$ are, respectively, the load and the contact surface area between the indenter tip and the sample.

\section{\begin{tabular}{l|l}
3 & RESULTS
\end{tabular}}

\section{1 $\mid$ Non-contact thermal poling treatment and DBD}

We first focus on the description of non-contact poling treatment conditions (geometry, voltage, induced current and gas discharge/plasma emission). Please note that in this study, the poling geometry and voltage are fixed for all the experiments. Figure 1B presents for the glass poled under nitrogen and without contact the curves of the applied voltage and the measured current as a function of time. Figure 1B represents the emission spectrum collected close to the anode. This spectrum corresponds to a gas discharge emission from second positive system (SPS) electronic transition of $\mathrm{N}_{2}\left(\mathrm{C}^{3}\right.$ $\left.\Pi_{\mathrm{u}} \rightarrow \mathrm{B}^{3} \Pi_{\mathrm{g}}\right)^{21,22}$

\section{2 $\quad$ Composition profile after poling treatment}

The composition profile of non-contact nitrogen poled glasses obtained by GD-OES and ToF-SIMS measurement is presented in Figure 2. In these two characterizations, the composition profile of the elements $\mathrm{Na}, \mathrm{Si}, \mathrm{Ca}, \mathrm{Mg}, \mathrm{K}, \mathrm{H}, \mathrm{Al}$, of the $\mathrm{N}_{2}$ Poled glasses is define by two layers. For the first layer, with a depth ranging from 200 to $400 \mathrm{~nm}$ of thickness, 
only silicon and a little bit of aluminum are detected, indicating the formation of a "silica-like" layer on the surface. The second layer is mainly composed of silicon, oxygen, but also magnesium and calcium, which are less mobile cations as compared to alkaline ions. This layer corresponds to an alkaline-earth silicate glass. At the interface between the second layer and the underlying bulk region, the concentrations of both potassium and sodium sharply rise with a strong accumulation of potassium just before the apparition of sodium. Bellow the interface, the intensity of the different elements return to levels close to those of the reference glass (Figure 3), showing the depth range of the poled region under the specific poling conditions. From the comparison of the profiles obtained by the two characterization techniques on a same nitrogen poled glass sample, one can observe that ToF-SIMS and GD-OES measurements are well correlated and consistent. Meanwhile, it is important to note that the composition profiles characterized by ToF-SIMS data exhibit relatively sharper transitions at interfaces since the shape of the crater is flat while it is cambered for GD-OES. Hence, there are slight deviation on the depth of the different interface. Interestingly, silicon and aluminum profiles are similar, showing that the aluminum ions are not affected by the poling treatment. One can also observe small change in intensity for ToF-SIMS silica profile, which has been discussed by different authors recently. For Kaasik et al, ${ }^{23}$ this change in intensity is attributed to a composition effect since the migration of silicon ions is not expected during a poling treatment. Upon this, the composition profile should be corrected, taking the silicon atom as a reference and considering it constant all along the profile. While for Smith et al, ${ }^{24}$ this change in intensity is likely originated to a densification of the "silica-like" layer on the surface, which results in the enhancement of the intensity at the surface. In our work, the comparison between ToFSIMS and GD-OES composition profiles can give some new insights on this important problematic. While matrix effects can modify the measured intensity in ToF-SIMS, such wellknown "artifact" are not expected for GD-OES, allowing the measured intensity of an element to be directly correlated to its concentration. Therefore, the observation in GD-OES data of a higher intensity for silica at the surface, indicates that the volume concentration of silica is higher on the surface of

\section{Poling without contact in nitrogen}

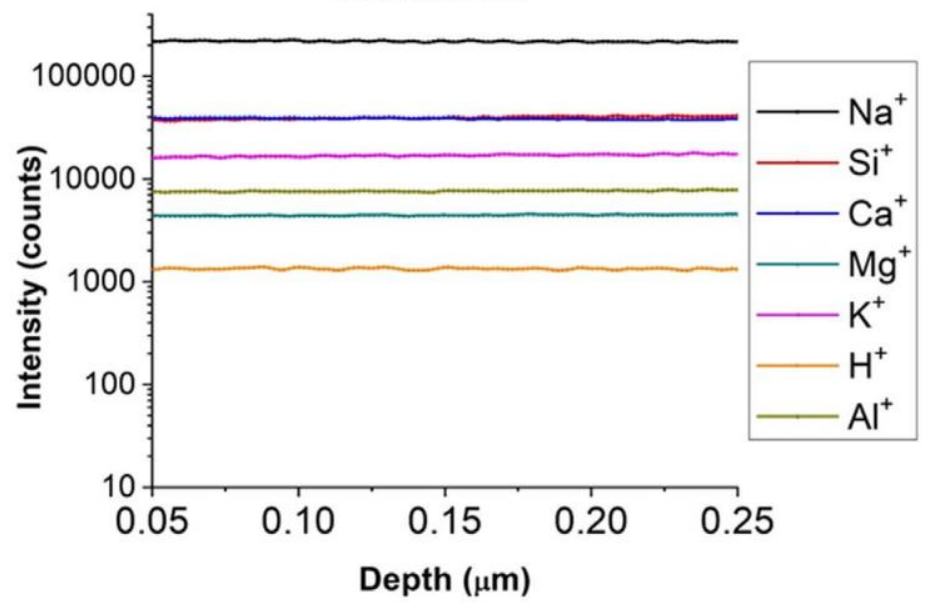

Poling without contact in air

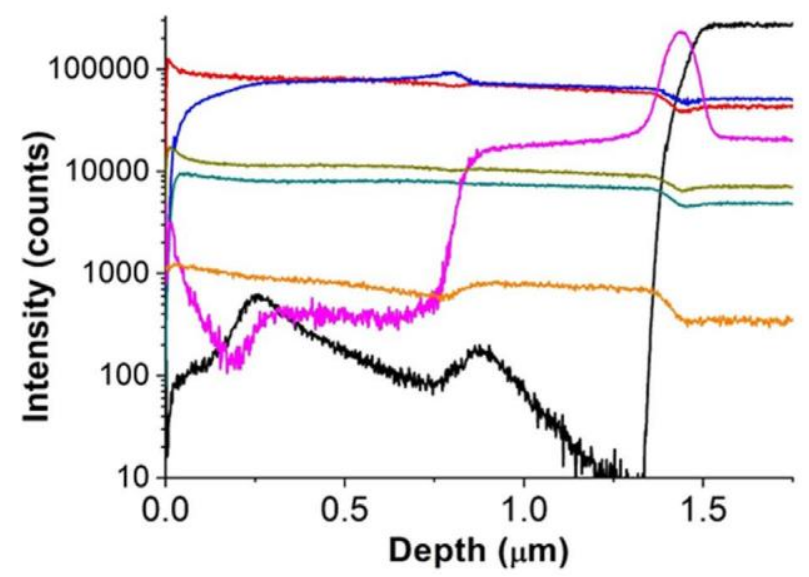

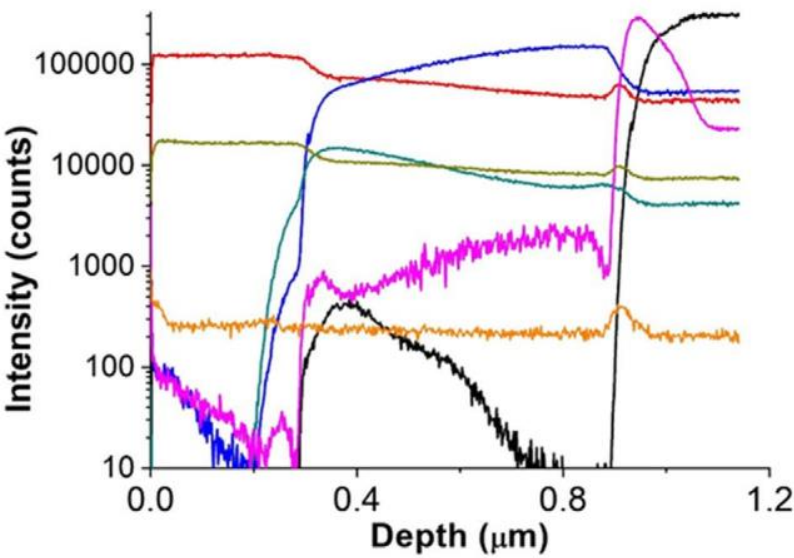

Poling with contact in nitrogen

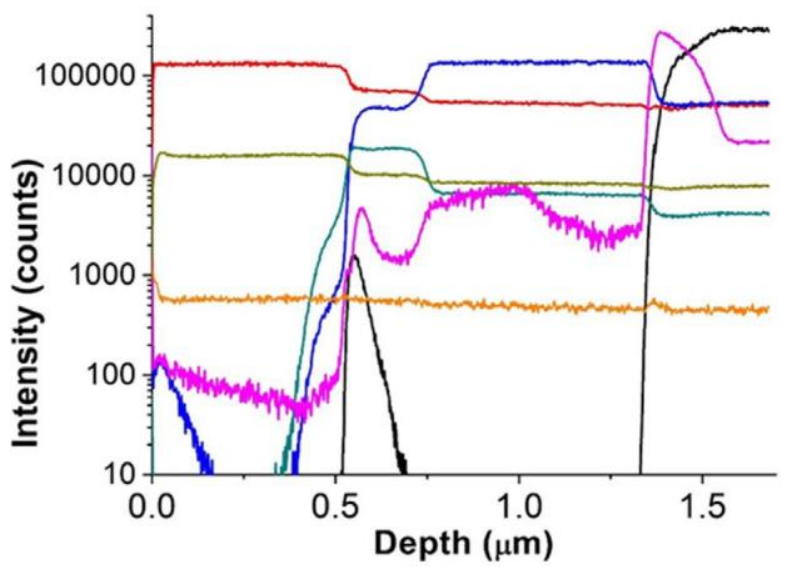

F I G U RE 3 ToF-SIMS composition profile in logarithmic scale of the reference glass (top left), non-contact air poled glass (bottom left), noncontact nitrogen poled glasses (top right), and contact nitrogen poled glasses (bottom right) 
nitrogen poled glasses with the formation of a densified silica layer through the process of thermal poling.

Figure 3 presents the ToF-SIMS composition profiles of the poled glass surfaces facing the anode and obtained under different poling conditions. Beneath the surface, a depletion
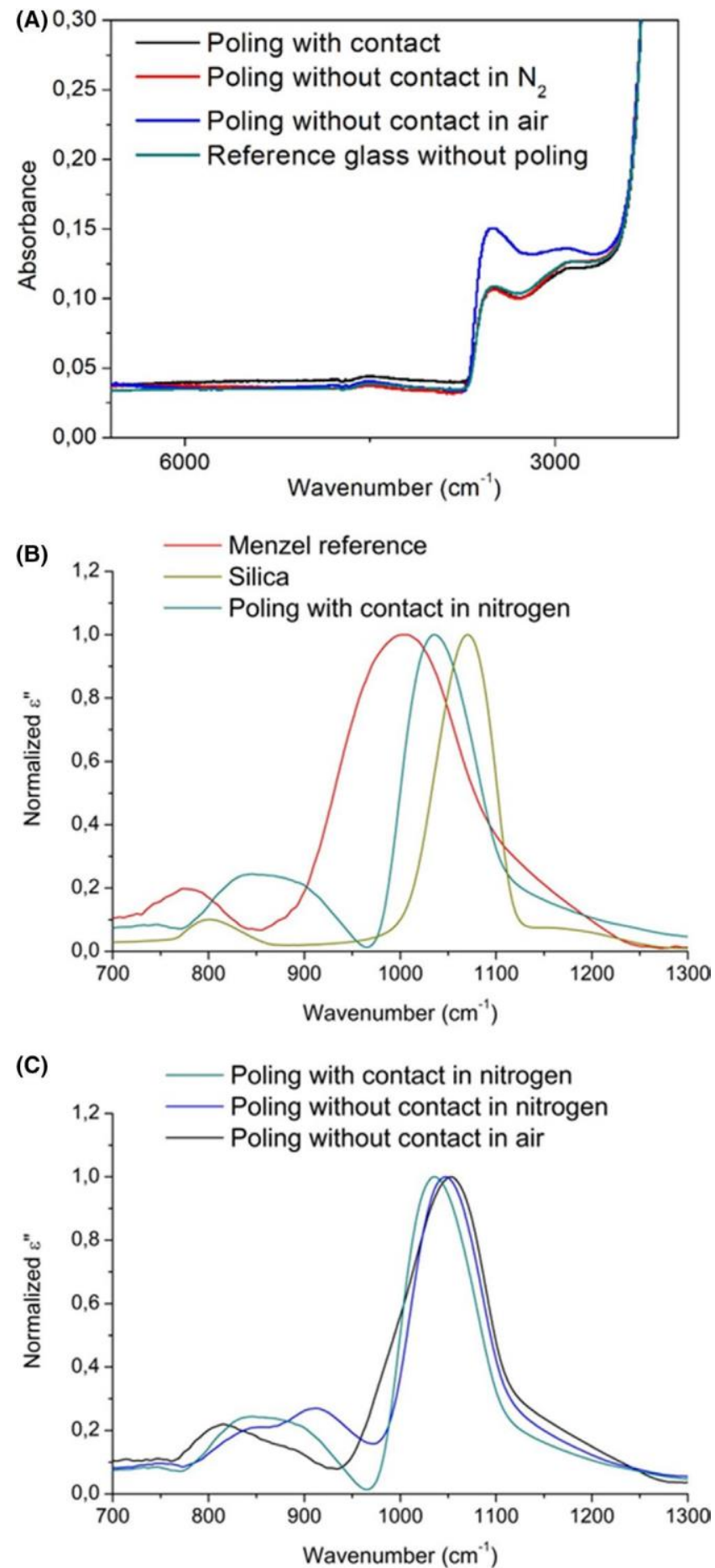

F I G URE 4 A, Absorbance curves of poled glasses having the same thickness; B, Normalized imaginary part of the electrical susceptibility of reference glasses and glass poled with contact in nitrogen, and $\mathrm{C}$, glasses poled with and without contact under air or nitrogen of mobile cations is observed, regardless of the method used (contact or non-contact). If we examine the element profile of non-contact air-poled glass, it is important to notice that contrary to nitrogen poled glasses, the air-poled glass does not exhibit the migration of alkaline-earth elements. Only sodium and potassium ions migrate through the applied electric field towards a higher depth as compare to that in nitrogen poled glasses. One should notice that the hydrogen intensity level is much higher in air-poled glass than in nitrogen poled glasses. The interface between the layer and the bulk glass composition is similar to the one observed for nitrogen poled glasses, with a sharp increase and an accumulation of potassium up to a depth where the concentration of sodium returns to its reference value.

\section{3 $\quad$ Surface chemical structure}

Figure 4A presents the IR absorbance curves of poled glasses measured in transmission mode. In these spectra, the glass' multiphonon absorption cut-off is observed at $2400 \mathrm{~cm}^{-1}$. Two additional absorptions are observed at 2880 and $3500 \mathrm{~cm}^{-1}$. The band at $2880 \mathrm{~cm}^{-1}$ is believed to be part of combinations of modes or overtones of silicate network, ${ }^{25}$ while the band at $3500 \mathrm{~cm}^{-1}$ is ascribed to vibrational mode of $\mathrm{OH}$ groups in silanol groups $\mathrm{Si}-\mathrm{OH}$ or water molecules within the glassy matrix. An increase in absorbance of the band at $3500 \mathrm{~cm}^{-1}$ is observed for the air poled glass as compared to that for the reference glass. Nitrogen poled glasses did not present any difference with the reference.

Figure 4B,C present the imaginary part of the dielectric constant of poled glasses extracted by Kramers-Kronig from reflectance measurement and normalized over the maximum peak intensity in the region $700-1300 \mathrm{~cm}^{-1}$. The very large band observed in the spectral range $900-1150 \mathrm{~cm}^{-1}$ is linked to anti-symmetric stretching of Si-O bonds, while at lower frequency the smaller band in the range $790-820 \mathrm{~cm}^{-1}$ is commonly ascribed to $\delta_{\mathrm{Si}-\mathrm{O}-\mathrm{Si}}$ deformation mode. The main large band can be deconvoluted into four components at 965, 1030, 1110 , and $1190 \mathrm{~cm}^{-1}$ which are attributed, respectively, to anti-symmetric stretching modes of $\mathrm{Q}^{2}$ and $\mathrm{Q}^{3}$ silicate entities as well as to anti-symmetric $\mathrm{AS}_{1}$ and $\mathrm{AS}_{2}$ modes of $\mathrm{Q}^{4}$ units ${ }^{26,27}$ $\left(Q^{n}\right.$ units are silicon tetrahedral $\mathrm{SiO}_{4}$ where $\mathrm{n}$ is the number of bridging oxygens forming $\mathrm{Si}-\mathrm{O}-\mathrm{Si}$ links and the others are non-bridging oxygens (NBOs) $\mathrm{Si}^{-} \mathrm{O}^{-}$). The reference glass spectrum has a main band position peaking at $1003 \mathrm{~cm}^{-1}$ and an important full-width half maximum that confirms that this soda lime silicate glassy network is composed of a majority of $\mathrm{Q}^{3}$ units but also presents a non-negligible amount of $\mathrm{Q}^{2}$ and $\mathrm{Q}^{4}$ entities. A pure silica sample is used as a second reference for the IR assignment showing the $\mathrm{AS}_{1}$ antisymmetric stretching mode of $\mathrm{Q}^{4}$ species at $1072 \mathrm{~cm}^{-1}$. As compared to the reference soda lime silicate glass, the main peak 
position of poled glasses spectra (Figure 2C) is shifted toward higher frequencies: $1036 \mathrm{~cm}^{-1}$ for the nitrogen poled glass in contact with the electrode, $1049 \mathrm{~cm}^{-1}$ for the nitrogen poled glass without contact, and $1053 \mathrm{~cm}^{-1}$ for the air-poled glass without contact. Considering the weak penetration of IR photon in this spectral range of strong absorption (around $20000 \mathrm{~cm}^{-1}$ ), this indicates a structural rearrangement of the glass surface with the conversion of $\mathrm{Q}^{2}$ and $\mathrm{Q}^{3}$ tetrahedral units in $\mathrm{Q}^{4}$ species. For air-poled glass, this main band presents a shoulder around $975 \mathrm{~cm}^{-1}$, which implies that some of the $\mathrm{Q}^{2}$ and $\mathrm{Q}^{3}$ species remain in the poled layer.

\subsection{Chemical durability and mechanical properties of poled glassy surfaces}

Figure 5 presents pictures of the surface of a reference, an airpoled glass and a non-contact nitrogen poled glass before and after a chemical durability test. All samples present a good surface quality before the accelerated ageing test, as shown by the absence of substantial defects on their surfaces. After two days in saline water, we clearly observe a degradation of the surface for the reference and the air-poled glass. Since saline water is known to be a corrosive medium for soda lime silicate glasses, it is expected that the reference glass is corroded. $^{28}$ The surface of air-poled glass undergoes degradation but at a lower level than the reference. On the other hand, both nitrogen poled glasses maintain a good surface quality, demonstrating a higher chemical resistance to saline water.

Figure 6 presents the hardness values of all samples before and after durability tests as a function of the indentation depth. For poled glasses it is important to note that indentation depths exceed the $10 \%$ value of the layer thickness that is usually accepted to ensure that the measurements are not affected by substrate values ${ }^{29}$ (the bulk in our case). Therefore, the obtained hardness value must be taken with precaution. However, it is still possible to compare the results with respect to each other, within a standard deviation of $12 \%$ at $1 \mathrm{mN}(\approx 70 \mathrm{~nm})$ and $4 \%$ at $5 \mathrm{mN}(\approx 180 \mathrm{~nm})$. The set of samples can be classified depending on their mechanical properties. The first group, having the highest mechanical properties (around $10 \mathrm{GPa}$ ), is composed of glasses, all poled under nitrogen: contact and non-contact poled glasses as well as contact poled glass after a chemical test. The hardness value is comparable to those of fused silica tabulated between 9 and $10 \mathrm{GPa}$ depending the authors. ${ }^{30,31}$ The second group, composed of the reference and non-contact air-poled glasses before and after durability tests, shows hardness values around $8 \mathrm{GPa}$, which is comparable to soda lime silicate's hardness values reported in the literature. ${ }^{15,20}$ The non-contact nitrogen poled glass after two days in saline waters exhibits an intermediate hardness. One can see that the hardness decreases with the indentation depth, except for the group where its hardness attains the reference glass' value.

\section{\begin{tabular}{l|l}
4 & DISCUSSION
\end{tabular}}

This work shows that the use of a Dielectric Barrier Discharge induced by a DC voltage along with an atmospheric control can improve the mechanical properties and the chemical durability of soda lime silicate glass surfaces. Both aspects (a) surface properties and (b) sustainability of the DC plasma should be discussed and related to the polarization mechanisms of the glass matrix. As observed in IR reflectance and ToF-SIMS data, soda lime silicate glasses either poled with or without contact under $\mathrm{N}_{2}$, have shown similar depleted layers of alkaline ions and similar

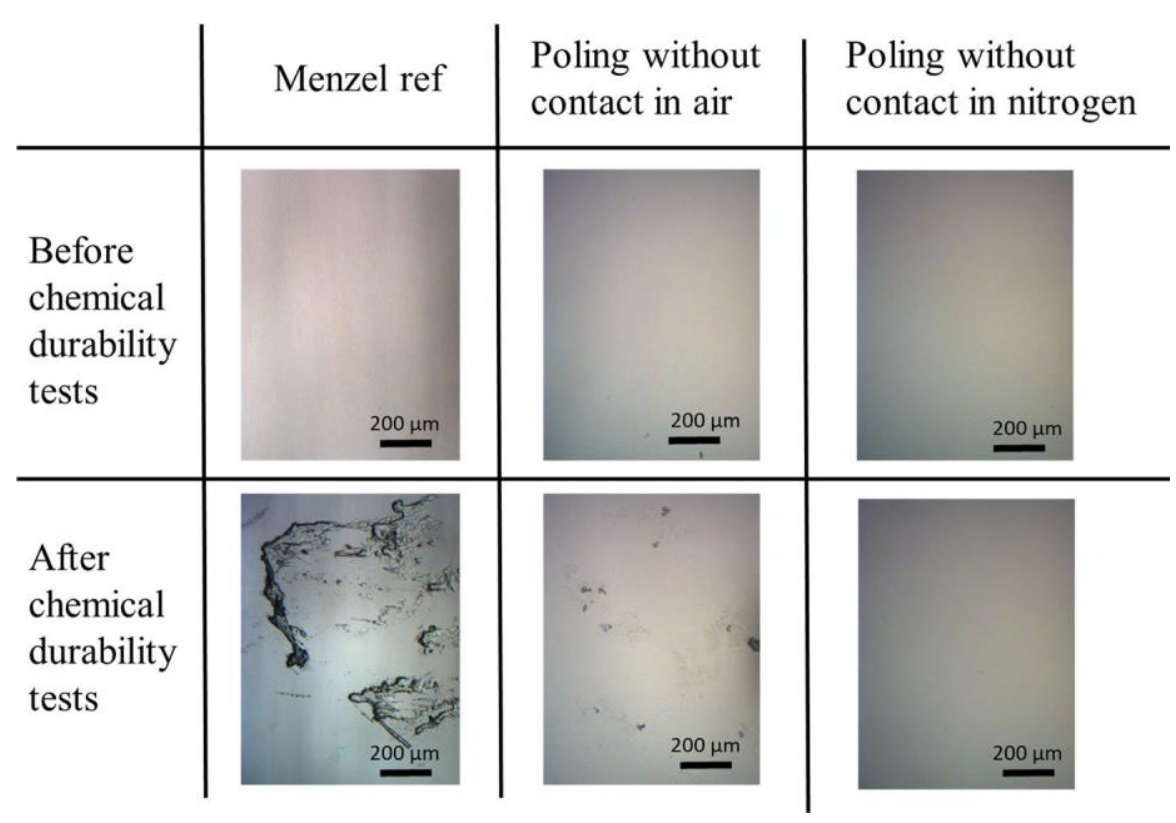

FIGURE 5 Optical images of glass surfaces before (top) and after (bottom) immersion in saline water during $2 \mathrm{~d}$ of reference glass (left), glass poled without contact in air (middle) and glass poled without contact under nitrogen (right). Note that results from the poled glass with contact under nitrogen were not presented as they were similar to those of non-contact nitrogen poled glasses 
F I G URE 6 Hardness as a function of the nanoindentation depth for poled and reference glasses before and after $2 \mathrm{~d}$ in saline water; acronyms NPG is for Nitrogen Poled Glass, APG for Air Poled Glass and SW for Saline Water. Error bars for $x$ axis (depth) were too small to be added in the figure

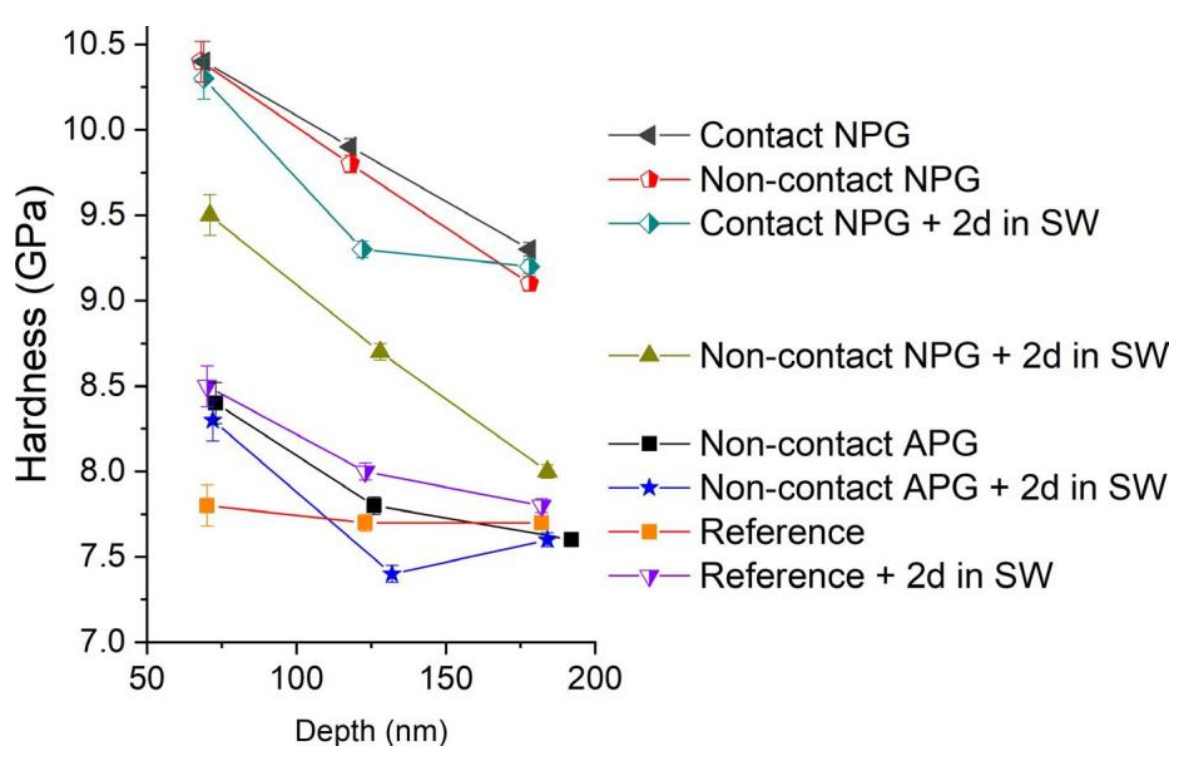

structural rearrangements of the silicate like network. It denotes that the charge carriers involved in the polarization mechanisms of the glass matrix should be comparable in both cases, that is, poling in contact or through the formation of DC gas discharges.

Here, we discuss the poling mechanisms in cations-rich oxide glasses. The pioneer works concerning polarization processes of alkali-ion-rich glasses have been published by Carlson et al in the $70 \mathrm{~s} .{ }^{17}$ It was experimentally demonstrated that a depletion of mobile ions is formed at the anode side of the poled glass which departure can be compensated either by an injection of positively charged species from the atmosphere such as $\mathrm{H}_{3} \mathrm{O}^{+} / \mathrm{H}^{+}$ions or by the drift toward the anode surface of negatively charged oxygen ions. ${ }^{14}$ Later, Krieger et al were the first to evoke the importance of an ionic conductivity during the formation of the space charge layer. ${ }^{32}$ Up to now, the mechanisms of negative charge motion involving either electronic or anionic conductivities as well as structural rearrangements of the glassy network and trapping of molecular oxygen are still unclear. Two mechanisms have been proposed based on either redox processes or the formation of peroxide radicals. ${ }^{33,34}$ Nevertheless, in both cases an electronic conduction of the oxide glass is involved when the internal electric field reaches values close to the dielectric breakdown. These studies indicate that the polarization treatments can be considered as blocking anode conditions since no proton injection is detected by IR (Figure 4A) for all experiments performed under a nitrogen atmosphere.

Meanwhile, for the air-poled glass, the structural reorganization of the glass matrix shows both (a) a polymerization of the silicate network through the formation of $\mathrm{SiO}_{2}$-like structural units (Figure 4) and (b) the injection of hydroxyl groups (absorbance increase of $\mathrm{OH}$ stretching modes at $3500 \mathrm{~cm}^{-1}$ in Figure 4A and ToF-SIMS measurements in Figure 3). It denotes that under air, both compensation mechanisms, that is, negative charge motion through a structural polymerization and positive charge injection from the atmosphere, take places during the treatment. Thus, the poling process for the air-poled glass can be considered as semi-blocking anode conditions. In addition to the occurrence of these two compensation mechanisms in air-poled glass, one can point out that alkaline-earth ions are not depleted at the anodic surface as compared to nitrogen poled glass where the layer is completely depleted for both alkaline and alkaline earth cations. On similar glasses the frozen internal field measured by quantitative second harmonic generation characterizations has shown a difference of one order of magnitude between poling treatments done under air or Argon. ${ }^{14}$ It denotes that the internal field strength difference between open and blocking anode poling conditions could explain the remaining of alkaline-earth cations in the poled layer for the treatment done without contact under air.

\section{\begin{tabular}{l|l}
4.1 & Surface properties of poled glasses
\end{tabular}}

The ageing behavior in saline water points out the importance of the poling atmosphere on the surface durability. This is evidenced by the loss of surface quality (Figure 5) observed for the air-poled glass after the ageing study. On the contrary, the surface quality of nitrogen poled glasses are preserved. Indeed, the surface composition of the air-poled glass, due to the semi blocking anode condition, can be considered as inhomogeneous with the formation of an alkaline-earth silicate network partially hydrated. This level of hydration of the silicate network, induced by the polarization in air, is certainly the main factor leading to the lower chemical durability observed for the air-treated glass. At the opposite, the "silica-like" layer observed for nitrogen poled glasses is not accompanied by hydroxyl group injection. The polarized 
layer acts then as a protection against the chemical ageing in saline water.

In addition to the enhancement of chemical stability, the "silica-like" layers formed at the surface induce a significant improvement of the hardness (only if the injection of hydroxyl group is avoided). One should point out that the hardness of the reinforced poled surfaces is close to the value of fused silica, tabulated between 9 and $10 \mathrm{GPa}^{30,31}$ The hardness enhancement of the surface could be also related to the densification of the silica layer, as observed by GD-OES.

Nevertheless, the conditions used to obtain this silica-like layer are not comparable to a classical melt-quenching process, since those conditions involve a very low temperature $\left(260^{\circ} \mathrm{C}\right)$ and a strong electrical constrain. The IR-reflectance study indicates structural differences between the poled silica-like layer and a pure silica glass made in regular conditions. One can particularly point out the peak position of the main stretching mode active in IR $\left(\mathrm{AS}_{1} \mathrm{v}_{\text {asSi-O }}\left(\mathrm{Q}^{4}\right)\right)$ as a function of the process conditions and as compared to silica. Recently, Luo et al, ${ }^{35}$ proposed an explanation based on molecular dynamics simulations, where the maximum frequency was mainly correlated to the Si-O bond length. A shift toward higher frequency corresponds to a decrease in $d_{\text {Si-O }}$ bond length while a shift toward lower frequency is associated with an increase in bond length. If the glass is composed only of $\mathrm{Q}^{4}$ silica species, the $d_{\mathrm{Si}-\mathrm{O}}$ bond length should affect the network density, upon this explanation, the "silica-like" layer obtained for nitrogen poled glasses is expected to be less dense than the one of pure silica, as the main peaks position of these samples are shifted toward lower frequencies as compared to silica.

Still, the measured hardness for poled glasses under nitrogen atmosphere is close to that of pure silica glass, which is in contradiction with the lower density expected form IR measurements. In such a case, there could be effects from the second layer where an accumulation of alkaline earth cations is observed. Such a stacking effect of large cations such as $\mathrm{Ca}^{2+}$ or $\mathrm{Mg}^{2+}$ may induce some compression effect which can strengthen the glassy structure. ${ }^{36}$ Under these assumptions, the improvement of mechanical properties could be linked to a multilayer effect with the first $\mathrm{SiO}_{2}$-like layer at the surface and the second one enriched with alkaline earth. The presence of remaining aluminum ions in the "silica-like" layers may also play a role in the strengthening of the glass surface' mechanical properties as their relative concentration increase in the silica-like layer compare to the initial soda lime silica glass. Finally, one of key results in this study is to obtain these improvements without contact, through a plasma between the anode and the soda lime silicate glass. The next section will correlate the glass polarization mechanisms and the nature of this plasma.

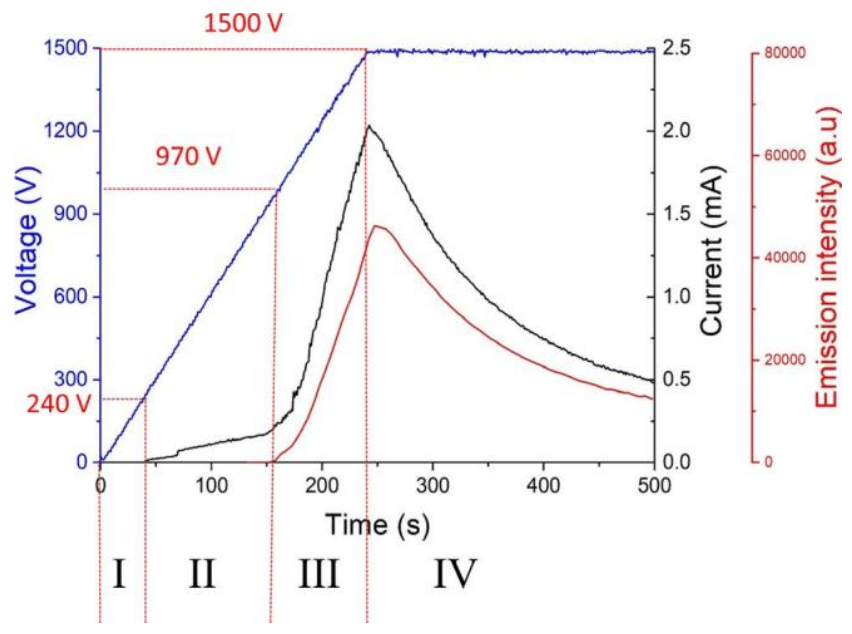

F I G U RE 7 Graphic presenting the curves of the applied voltage, the measured current and the transition $(0-1)$ of the SPS $(357 \mathrm{~nm})$ as a function of time. The fourth regions corresponding to different regimes are also represented

\section{2 $\quad$ Relation between thermal poling of glass and plasma micro-discharge}

By polarizing a soda lime silicate glass without direct contact between the anode and the glass surface, a significant light emission from gas discharge is observed for more than 30 minutes under a DC electrical constrain. The emission spectra $(300-500 \mathrm{~nm})$ is dominated by the second positive system electronic transition of $\mathrm{N}_{2}(\mathrm{C} 3 \Pi \mathrm{u} \rightarrow \mathrm{B} 3 \Pi \mathrm{g})$ typically observed for "cold" plasma generated within a corona or a dielectric barrier discharge (DBD) in nitrogen or air at atmospheric pressure. ${ }^{22}$ During the experiment we followed the evolution of the transition $\left(v^{\prime}-v^{\prime \prime}\right)=(0-1)$ of the emitted signal at $357 \mathrm{~nm}$. Figure 7 shows the different phases observed on the voltage-current and emission curves as a function of time, which are divided in four regions. In the first one (I), no current or light emission was detected. The second region (II) is related to the discharge ignition. When the voltage reached a threshold value of $240 \mathrm{~V}$, a current (corresponding to surface and bulk charges) starts to be measured, which is consistent with the minimum sparking constant in our experimental conditions in $\mathrm{N}_{2} \cdot{ }^{37}$ However, no light emission was observed in this regime. The conjunction of a small current increase and the absence of gas emission lines could be characteristic of a dark discharge in a Townsend regime. ${ }^{38}$ The third region (III) is characterized by the combination of a significant increase of the current and the observation of nitrogen plasma emission. These observations indicate a transition from dark discharge (in region II) to glow discharge between the anode and the glass sample (as observed in Figure 1A). The fourth region (IV) begins after the target voltage of $1500 \mathrm{~V}$ is reached. The evolution of the current over time in region IV is comparable to the ones obtained during contact thermal 
poling experiments. In our case, the glow discharge was stable and visible until the end of poling treatment.

Usually, in order to ensure a stable DBD, alternative or pulsed current ${ }^{39,40}$ are used to avoid charge accumulations on the dielectric surface. Such accumulation could lead to a drop of the gas tension and the extinction of the plasma or formation of an electric arc that could damage the dielectric. In our experiment, direct current is employed and a stable plasma is observed throughout the poling experiment c.a for 30 minutes. To explain the sustainability of the plasma, the nature of the dielectric is essential. Generally, $\mathrm{Al}_{2} \mathrm{O}_{3}$ or silica is used in DBD configuration. However, in our case the soda lime silicate glass used contains a large number of ionic mobile species, which are able to release two negative charge carriers under the influence of the plasma, either secondary electrons or anions. Under the impingement of ionic and metastable species from the plasma, the surface of the cathode, in our case the soda lime silicate, releases secondary electrons. These electrons are accelerated in the electric field and maintain the discharge ${ }^{41}$. At the glass surface both anions and electrons neutralize positively charged species from the gas discharge avoiding a screening of the applied electric field and preventing arc formation. Such interactions between charge carriers formed in discharges occurring either in the gas or in the poled glass matrix were discussed by Cremoux et $\mathrm{al}^{34}$ and Luo et $\mathrm{al}^{15}$ upon observing $\mathrm{NO}^{+}, \mathrm{NO}_{2}$ and $\mathrm{N}_{2} \mathrm{O}_{4}$ species trapped below the poled glass surface. Finally, as observe in Figure 7, the evolution of the light emission curve of the (0-1) transition at $357 \mathrm{~nm}$ shows similar trend with the current curve, which is relied to the formation of the poled layer that is a reservoir of electrons and anions.

\section{5 | CONCLUSION}

In this study, we demonstrate that, depending on the atmosphere, non-contact thermal polarization of soda lime glass has a significant impact on the durability and the surface hardness of glasses. The use of $\mathrm{N}_{2}$ gas in the chamber, regardless of the method used (contact or non-contact), enhances the chemical durability and the surface hardness properties of soda lime glass as compared to air poled or soda lime silicate reference glasses. It has been shown that under the absence of water molecules in the gas, a "silica-like" layer is formed at the surface of the soda lime silicate glass. This "silica-like" layer leads to a strengthened and chemically more resistant glass surface. On the other hand, the presence of water (poling under air) indicates the introduction of protons beneath the glass surface, involving the formation of a hydrated alkalineearth silicate network, less resistant to corrosion and mechanically comparable to the initial soda lime silicate glass. The IR structural characterization of the glass surface reveals that the thermal polarization of glass using a plasma (non-contact thermal poling) leads to a less dense "silica-like" layer compare to pure silica, while the measured hardness is in the same range. In order to explain the sustainability of the plasma during the poling treatment, we proposed a mechanism based on the structural rearrangement of the glass and the movement of ionic species inside the soda lime silicate glass. However, further investigation is needed to elucidate the interaction of the plasma with the soda lime silicate glass surface.

\section{ACKNOWLEDGMENT}

The authors thank the financial support of IdEx Bordeaux (Cluster of Excellence LAPHIA and the allocated grant referred to as ANR-10-IDEX-03-03), the project POLARGLASS from the SATT Aquitaine and the CNRS project EMERGENCE @INC2019. This work was supported by the région Nouvelle Aquitaine (Grant SOLR2). This project has received funding from the European Union's Horizon 202 research program under the Marie SkłodowskaCurie grant agreement No 823941 (FUNGLASS). This work was partly supported by the French RENATECH network. All IR experiments have been performed at the platform SIV at University of Bordeaux, funded by the FEDER and the Region Aquitaine. The authors would like to thank Fabienne Ibalot (Univ. Bordeaux, CNRS, PLACAMAT, UMS 3626, PESSAC, France) for her technical support on GD-OES measurements.

\section{ORCID}

Matthieu Chazot : https://orcid.org/0000-0001-8120-0423

\section{REFERENCES}

1. Paraillous M. Traitement de surface et revêtement transparent sur verre sodo-calcique. Université de Bordeaux. 2016.

2. Senturk U, Varner JR, LaCourse WC. Structure-hardness relation for high-temperature $\mathrm{SO}_{2}$-dealkalized float glass. J Non Cryst Solids. 1997;222:160-6.

3. Leboeuf V, Blondeau JP, De Sousa MD, Véron O. Potassium ionic exchange in glasses for mechanical property improvement. J Non Cryst Solids. 2013;377:60-5.

4. Luo J, Huynh H, Pantano CG, Kim SH. Hydrothermal reactions of soda lime silica glass - revealing subsurface damage and alteration of mechanical properties and chemical structure of glass surfaces. J Non Cryst Solids. 2016;452:93-101.

5. Talimian A, Mariotto G, Sglavo VM. Electric field-assisted ion exchange strengthening of borosilicate and soda lime silicate glass. Int J Appl Glas Sci. 2017;8(3):291-300.

6. Rodriguez V, Guery G, Dussauze M, Adamietz F, Cardinal T, Richardson K. Raman gain in tellurite glass: how combination of IR, Raman, hyper-Raman and hyper-Rayleigh brings new understandings. J Phys Chem C. 2016;120(40):23144-51.

7. Lepicard A, Bondu F, Kang M, Sisken L, Yadav A, Adamietz F, et al. Long-lived monolithic micro-optics for multispectral GRIN applications. Sci Rep. 2018;8(7388):1-8.

8. Dussauze M, Rodriguez V, Velli L, Varsamis CPE, Kamitsos EI. Polarization mechanisms and structural rearrangements in 
thermally poled sodium-alumino phosphate glasses. J Appl Phys. 2010;107(043505).

9. Dussauze M, Kamitsos EI, Fargin E, Rodriguez V. Structural Rearrangements and second-order optical response in the space charge layer of thermally poled sodium - niobium borophosphate glasses. J Phys Chem C. 2007;111(39):14560-6.

10. Dussauze M, Cremoux T, Adamietz F, Rodriguez V. Thermal poling of optical glasses: mechanisms and second-order optical properties. Int J Appl Glas Sci. 2012;3(4):309-20.

11. Smith NJ, Regier T, Dutta I. Structure and composition of surface depletion layers in poled aluminosilicate glasses. J Am Ceram Soc. 2019;102(6):3037-62.

12. Sokolov K, Melehin V, Petrov M, Zhurikhina V, Lipovskii A. Spatially periodical poling of silica glass. J Appl Phys. 2012;111(104307).

13. Dussauze M, Rodriguez V, Adamietz F, Yang G, Bondu F. Accurate second harmonic generation microimprinting in glassy oxide materials. Adv Opt Mater. 2016;4:929-35.

14. Dussauze M, Rodriguez V, Lipovskii A, Petrov M, Smith C, Richardson K, et al. How does thermal poling affect the structure of soda-lime glass? J Phys Chem C. 2010;114(29):12754-9.

15. Luo J, Bae S, Yuan M, Schneider E, Lanagan MT, Pantano CG, et al. Chemical structure and mechanical properties of soda lime silica glass surfaces treated by thermal poling in inert and reactive ambient gases. J Am Ceram Soc. 2018;101(7):2951-64.

16. He H, Luo J, Qian L, Pantano CG, Kim SH. Thermal poling of soda-lime silica glass with nonblocking electrodes - part 2: effects on mechanical and mechanochemical properties. J Am Ceram Soc. 2016;99(4):1231-8.

17. Carlson DE, Hang KW, Stockdale GF, Anode B. Ion depletion of glass at a blocking anode: II, properties of ion-depleted glasses. J Am Ceram Soc. 1974;57(7):295-300.

18. Ikutame N, Kawaguchi K, Ikeda H, Sakai D, Harada K, Funatsu $\mathrm{S}$, et al. Low-temperature fabrication of fine structures on glass using electrical nanoimprint and chemical etching. J Appl Phys. 2013;114(083514).

19. Kamenskii AN, Reduto IV, Petrikov VD, Lipovskii AA. Effective diffraction gratings via acidic etching of thermally poled glass. Opt Mater. 2016;62:250-4.

20. Oliver WC, Pharr GM. An improved technique for determining hardness and elastic modulus using load and displacement sensing indentation experiments. J Mater Res. 1992;7(6):1564-83.

21. Gherardi N, Gouda G, Gat E, Ricard A, Massines F. Transition from glow silent discharge to micro-discharges in nitrogen gas. Plasma Sources Sci Technol. 2000;9(3):340-6.

22. Meiners A, Leck M, Abel B. Multiple parameter optimization and spectroscopic characterization of a dielectric barrier discharge in N2. Plasma Sources Sci Technol. 2009;18(4).

23. Kaasik VP, Lipovskii AA, Raskhodchikov DV, Reshetov IV, Tagantsev DK. How to reveal the correct elemental concentration profiles in poled multicomponent silicate glasses from the data of secondary ion mass spectrometry (SIMS). J Non Cryst Solids. 2019;503-504:397-9.

24. Smith NJ, McLaren CT, Fahey AJ. Comments on "How to reveal the correct elemental concentration profiles in poled multicomponent silicate glasses from the data of secondary ion mass spectrometry (SIMS)”. J Non Cryst Solids. 2019;522(119547).

25. Efimov AM, Pogareva VG. IR absorption spectra of vitreous silica and silicate glasses: the nature of bands in the 1300 to $5000 \mathrm{~cm}^{-1}$ region. Chem Geol. 2006;229(1-3):198-217.
26. Kapoutsis JA, Kamitsos EI, Chryssikos GD, Yiannopoulos YD, Patsis AP. Alkali sites in silicate glasses. Chim Chronica, New Ser. 1994;23:341-6.

27. Kamitsos EI, Patsis AP, Kordas G. Infrared-reflectance spectra of heat-treated, sol-gel-derived silica. Phys Rev B. 1993;48(17):12499-505.

28. Carmona N, García-Heras M, Gil C, Villegas MA. Chemical degradation of glasses under simulated marine medium. Mater Chem Phys. 2005;94(1):92-102.

29. Pharr GM, Oliver WC. Measurement of thin film mechanical properties using nanoindentation. MRS Bull. 1992;17(7):28-33.

30. Gao C, Liu M. Instrumented indentation of fused silica by Berkovich indenter. J Non Cryst Solids. 2017;475:151-60.

31. Dahmani F, Lambropoulos JC, Schmid AW, Burns SJ, Pratt C. Nanoindentation technique for measuring residual stress field around a laser-induced crack in fused silica. J Mater Sci. 1998;33(19):4677-85.

32. Krieger UK, Lanford WA. Field assisted transport of $\mathrm{Na}^{+}$ions, $\mathrm{Ca}^{2+}$ ions and electrons in commercial soda-lime glass I: experimental. J Non Cryst Solids. 1988;102(1-3):50-61.

33. Redkov AV, Melehin VG, Lipovskii AA. How does thermal poling produce interstitial molecular oxygen in silicate glasses? J Phys Chem C. 2015;119(30):17298-307.

34. Cremoux T, Dussauze M, Fargin E, Cardinal T, Talaga D, Adamietz $\mathrm{F}$, et al. Trapped molecular and ionic species in poled borosilicate glasses: Toward a rationalized description of thermal poling in glasses. J Phys Chem C. 2014;118(7):3716-23.

35. Luo J, Zhou Y, Milner ST, Pantano CG, Kim SH. Molecular dynamics study of correlations between IR peak position and bond parameters of silica and silicate glasses: effects of temperature and stress. J Am Ceram Soc. 2018;101(1):178-88.

36. Varshneya AK. Chemical strengthening of glass: lessons learned and yet to be learned. Int J Appl Glas Sci. 2010;1(2):131-42.

37. RaselMia M, Fayzur Rahman M, Hasanuzzaman M, Rabia CT. Reduction of heavy metals in tannery waste water using high voltage discharge. Int J Appl Inf Syst. 2015;9(4):32-41.

38. Massines F, Gherardi N, Naudé N, Ségur P. Glow and Townsend dielectric barrier discharge in various atmosphere. Plasma Phys Control Fusion. 2005;47(12B):B577-88.

39. Tendero C, Tixier C, Tristant P, Desmaison J, Leprince P. Atmospheric pressure plasmas: a review. Spectrochim Acta - Part B At Spectrosc. 2006;61(1):2-30.

40. Corrigendum BR. Dielectric barrier discharges: progress on plasma sources and on the understanding of regimes and single filaments. Plasma Sources Sci Technol. 2018;27(7).

41. Massines F, Rabehi A, Decomps P, Ben GR, Ségur P, Mayoux C. Experimental and theoretical study of a glow discharge at atmospheric pressure controlled by dielectric barrier. J Appl Phys. 1998;83(6):2950-7. 